\title{
The Impact of Donor Type and Quality on Renal Transplant Outcomes
}

\author{
Hung Do Nguyen ${ }^{1}$, Kenneth Yong ${ }^{1,2}$, Rebecca Croke ${ }^{1}$ and Wai H Lim ${ }^{1,2}$ \\ ${ }^{1}$ Sir Charles Gairdner Hospital, Department of Renal Medicine, Western Australia \\ 2University of Western Australia, Western Australia \\ Australia
}

\section{Introduction}

Renal transplantation improves survival of patients with end-stage kidney disease (ESKD) (Wolfe, McCullough et al. 2009). In most countries, including the United States and Australia, there continues to be a growing disparity between the limited availability of deceased-donor kidneys compared to potential transplant candidates. In contrast, livedonor kidney transplantation has been steadily increasing over time. It has been well established that the type (live or deceased donor kidneys) and quality (donor age and presence of donor comorbidities) of donor kidneys have a significant impact on renal allograft outcomes. In this chapter, we will focus on both live-donor and deceased donor kidney transplantation and the impact of donor factors and types on graft and patient outcomes. With the continuing shortage of deceased donor kidneys coupled with a growing number of older transplant candidates, there has been a greater acceptance of using older donor kidneys, including increased utility of expanded criteria donor (ECD) and donation after cardiac death (DCD) kidneys. We will look at the impact of using ECD and DCD kidneys on graft and patient survival, and to identify modifiable factors that may improve transplant outcomes in recipients receiving ECD and DCD kidneys. Finally, we will discuss whether the implementation of utility-based allocation strategies for deceased donor kidneys is an appropriate way forward to provide a balance between utility and equity in the distribution of deceased donor kidneys.

\section{Live-donor kidney transplantation}

Since its introduction over 50 years ago, live-donor kidney transplantation is associated with better graft and patient outcomes compared with deceased donor kidney transplantation. The majority of live-related kidney transplantation is from siblings and parents, although spousal donation is becoming increasingly more common. There have been many live donor factors that have been identified which could affect transplant outcomes and this will be discussed in greater details in this chapter.

\subsection{Trends In live donor transplantation}

Live-donor renal transplantation has increased considerably over time, with some countries like the United States and Australia reporting an increase of at least $50 \%$ over the past 
decade(Horvat, Shariff et al. 2009). Even in countries without a deceased donor renal transplant program such as the Middle East and Asia, live-donor renal transplantation continues to grow substantially(Ghods and Savaj 2006; Horvat, Shariff et al. 2009). It is currently estimated that live-donor renal transplantation accounts for over $40 \%$ of total renal transplant numbers worldwide. According to the Australia and New Zealand Dialysis and Transplant (ANZDATA) Registry report, the proportion of live-donor renal transplantation has increased from 31\% in 1998 to 44\% in 2008 (Figure 1)(Campbell, McDonald et al. 2009). Similar increases have been reported in other countries including Europe and the United States (De Meester 1998; Oosterlee and Rahmel 2008; Horvat, Shariff et al. 2009; US Organ Procurement and Transplantation Network and Scientific Registry of Transplant Recipients 2009; ERA-EDTA Registry 2010).

Within the United States, Europe and Australia, the increased rates of live-donor renal transplantation are directly attributable to growth of live-unrelated donor (LURD) kidney transplants (Oosterlee and Rahmel 2008; Campbell, McDonald et al. 2009; US Organ Procurement and Transplantation Network and Scientific Registry of Transplant Recipients 2009; ERA-EDTA Registry 2010). In Australia, the proportion of LURD has increased substantially from $31 \%$ of overall live-donor transplants in 2000 to $50 \%$ in 2008 . The majority of live-related donor (LRD) kidney transplants are from parental or sibling donors, whereas spousal donation accounts for the majority of LURD transplants. Furthermore, the adoption of laparoscopic donor nephrectomy techniques coupled with low rates of short- and longterm complications of kidney donation has also contributed significantly to the expansion of live-donor transplantation (Bia, Ramos et al. 1995; Schweitzer, Wilson et al. 2000).

Finally, there is greater acceptance of older live-donors over the past decade despite donor age having been shown to affect renal transplant outcomes. In the United States, the proportion of older donors $>50$ years age has increased by almost $7 \%$ between 1999 and 2008, with similar proportional increase in other countries (US Organ Procurement and Transplantation Network and Scientific Registry of Transplant Recipients 2009).

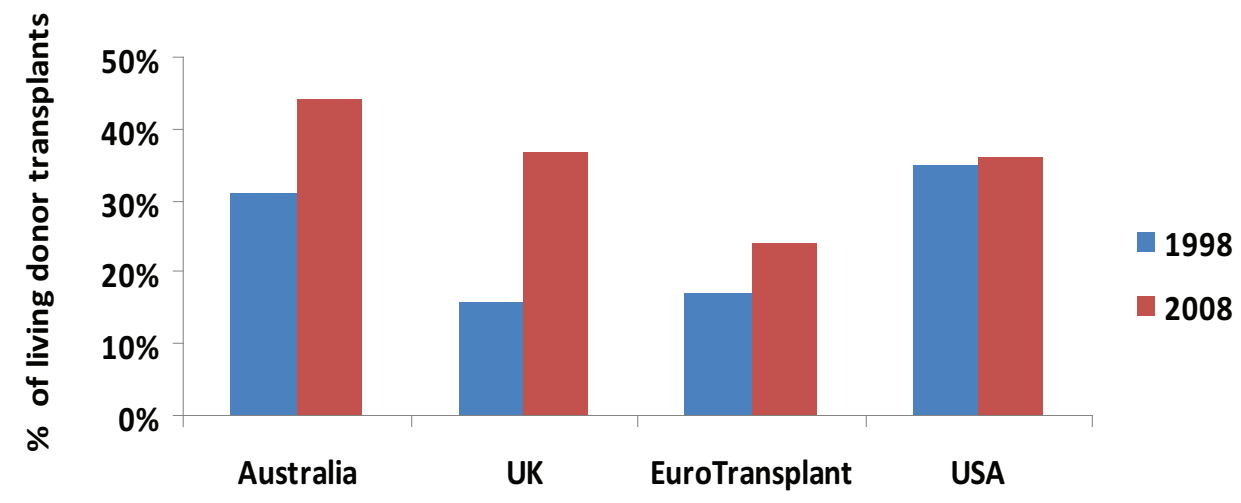

Fig. 1. Living donor transplants as proportion of total transplants. 


\subsection{Outcome of live compared to deceased-donor kidney transplantation}

Live-donor transplantation is associated with superior graft and patient outcomes compared with deceased-donor transplantation (Table 1) (Terasaki, Cecka et al. 1995; Gjertson and Cecka 2000; Campbell, McDonald et al. 2009; US Organ Procurement and Transplantation Network and Scientific Registry of Transplant Recipients 2009). In addition, the introduction of pre-emptive live-donor renal transplantation provides ESKD patients the option of avoiding dialysis (Mange, Joffe et al. 2001; Meier-Kriesche and Kaplan 2002; Liem and Weimar 2009). Finally, it has been established by several large single centre and registry studies that the superior outcomes of live-donor transplantation occur independently of human leukocyte antigen (HLA)-matching and donor or recipient characteristics (Terasaki, Cecka et al. 1995; Gjertson and Cecka 2000; Fuggle, Allen et al. 2010).

Large registry analyses from the United States, Europe and Australia have demonstrated a significant graft and/or patient survival advantage and possibly reduction in rejection risk in pre-emptive live-donor transplants compared to non-pre-emptive live-donor transplants, possibly related to avoidance of dialysis exposure (Donelly, Oman et al. 1995; Mange, Joffe et al. 2001; Milton, Russ et al. 2008). However, one study suggested that short duration of dialysis of $<90$ days prior to transplant had comparable graft survival to pre-emptive transplant recipients (Milton, Russ et al. 2008). Interestingly, unlike pre-emptive live-donor transplantation, pre-emptive deceased donor transplantation does not appear to be associated with improved graft or patient survival compared to non-pre-emptive deceased donor transplantation (Kessler, Ladriere et al. 2011).

$\begin{array}{ccc}1 \text { year graft / } & 5 \text { year graft / } & 10 \text { year graft / } \\ \text { patient } & \text { patient } & \text { patient } \\ \text { survival } & \text { survival } & \text { survival }\end{array}$

\begin{tabular}{|c|c|c|c|c|}
\hline \multirow{2}{*}{ Australia } & Live & $96.8 \% / 98.7 \%$ & $87.5 \% / 94.1 \%$ & $68.8 \% / 86.7 \%$ \\
\hline & Deceased & $91.6 \% / 96.4 \%$ & $80.8 \% / 89.0 \%$ & $58.6 \% / 72.6 \%$ \\
\hline \multirow{2}{*}{ United States } & Live & $95.7 \% / 98.3 \%$ & $80.4 \% / 90.2 \%$ & $57.0 \% / 76.5 \%$ \\
\hline & Deceased & $90.5 \% / 95.2 \%$ & $67.3 \% / 80.7 \%$ & $41.0 \% / 60.6 \%$ \\
\hline
\end{tabular}

Table 1. Unadjusted 1, 5 and 10-year graft and patient survival rates following primary living and deceased donor transplantation in Australia \& United States in 2008 (Campbell, McDonald et al. 2009; US Organ Procurement and Transplantation Network and Scientific Registry of Transplant Recipients 2009).

\subsection{Effect of donor characteristics on live-donor kidney transplant outcomes 2.3.1 Donor gender}

A disproportionately greater number of female donors have been observed in live-donor programs in most countries, including the United States and Australia(Kayler, MeierKriesche et al. 2002; Campbell, McDonald et al. 2009). In Australia, female donors accounted for $53 \%$ and $62 \%$ of overall LRD and LURD donors respectively, the latter likely to reflect the growth in spousal donation (Campbell, McDonald et al. 2009). The reason for the greater proportion of female donors remains unclear although differences 
in medical (higher rates of cardiovascular disease in men) and psychosocial (financial issues and differing perception towards donation between genders) factors may be contributing (Bloembergen, Port et al. 1996; Schaubel, Stewart et al. 2000; Zimmerman, Donnelly et al. 2000).

In deceased donor kidney transplants, female donors have been shown to be associated with higher rates of rejection, poorer post-transplant graft function and possibly reduced graft and patient survival (Vereerstraeten, Wissing et al. 1999; Zeier, Dohler et al. 2002). In livedonor kidney transplantation, large single centre studies have suggested that female donors are associated with a greater risk of rejection and poorer post-transplant graft function (Oien, Reisaeter et al. 2005; Oien, Reisaeter et al. 2007), but this association has not been observed in large registry analyses (Kayler, Rasmussen et al. 2003; Lim, Chang et al. 2007). The failure to account for differences in donor-recipient body mass in these studies may in part explain the conflicting results between studies. It is plausible that the inverse association between female donors and post-transplant graft function may be attributed to 'inadequate' nephron mass from smaller female donors into larger male recipients with subsequent hyperfiltration injury and decline in renal function (Brenner, Cohen et al. 1992; Brenner, Lawler et al. 1996). Supporting this explanation, Poggio et al demonstrated that donors with larger kidney volume (typically donors with larger body sizes and male donors), as determined by 3D helical computed tomography scanning, were associated with lower rejection risk and improved post-transplant radionuclide glomerular filtration rate (GFR) (Poggio, Hila et al. 2006). However, selective transplantation of donor and recipient pairs based on size-matching remains debatable.

\subsubsection{Donor-recipient relationship}

A number of large single centre studies and registry analyses including United Network of Organ Sharing (UNOS) and ANZDATA have demonstrated similar graft and patient outcomes between LRD and LURD transplants, even though LURD were more likely to be older donors and often have poorer HLA-matching (Figure 8)(Terasaki, Cecka et al. 1995; Gjertson and Cecka 2000; Humar, Durand et al. 2000; Lim, Chang et al. 2007). Early studies have indicated that husband-to-wife (Terasaki, Cecka et al. 1997; Rosenberg, Jones et al. 2004) and child-to-mother live-donor transplants were associated with an increased risk of rejection and graft failure (Cecka 1995; Mahanty, Cherikh et al. 2001), possibly related to prior exposure to donor HLA antigens during pregnancy (Miles, Schaubel et al. 2008; Fuggle, Allen et al. 2010). In a recent ANZDATA analysis of 1989 primary live-donor renal transplants between 1995 and 2004, Lim et al reported that the risk of graft and patient survival was similar between LRD and LURD transplants. In this study, parental donors were associated with an increased risk of acute rejection at 6 months (odds ratio [OR] 1.69, 95\% confidence interval [CI] 1.13-2.53) and lower GFR at 1 and 3 years post-transplant, but this did not translate to inferior graft or patient survival (Lim, Chang et al. 2007). In contrast, husband-to-wife and child-to-mother transplants were not associated with poorer graft outcomes in this study. Analysis of the UNOS database suggested that in recipients with genetic-predisposed ESKD such as focal segmental glomerulosclerosis (FSGS), type I diabetes and polycystic kidney disease (PKD), LRD kidney transplants may be associated with poorer graft outcomes compared with LURD transplants but this association remains debatable (Futagawa, Waki et al. 2005). 


\subsubsection{Expanded-criteria live donors}

As with deceased donors, certain live donor characteristics have been identified that may have a significant impact on renal allograft outcomes. The identification of these donor characteristics in the assessment of potential live donor-recipient pairing may help in the selection of the most appropriate live donor to achieve the best graft outcomes. A large retrospective chart review of 264 live donor-recipient pairs transplanted between 1997 and 2003 at Cleveland clinic demonstrated that older donor age $\geq 45$ years (compared with $<45$ years), donor radionuclide GFR $\leq 110 \mathrm{~mL} / \mathrm{min}$ (compared with $>110 \mathrm{~mL} / \mathrm{min}$ ), donor systolic blood pressure $\geq 120 \mathrm{mmHg}$ (compared with $<120 \mathrm{mmHg}$ ) and donor cholesterol $\geq 200 \mathrm{mg} / \mathrm{dL}$ (compared with $<200 \mathrm{mg} / \mathrm{dL}$ ) were associated with a greater risk of acute rejection, delayed graft function (DGF), poorer post-transplant graft function and/or graft loss at 2 and 3 years post-transplantation in the adjusted model. What was interesting about this study were the additive negative effects of increasing number of donor factors on graft function. In this study, there was no association between donor uric acid, fasting glucose, gender or race and graft outcomes (Issa, Stephany et al. 2007). Other studies have demonstrated a similar strong independent relationship between live donor GFR and post-transplant graft function (Poggio, Hila et al. 2006).

The recent meta-analyses by Iordanous $Y$ et al of living expanded criteria kidney donors demonstrated that older live donors were associated with poorer composite outcomes of graft and patient survival compared to younger donors (meta-analysis of 12 studies, $72 \%$ vs. $80 \%$, unadjusted relative risk [RR] of survival $0.89,95 \%$ CI $0.83-0.95)$. However, the association between donor age and survival appeared to diminished over time (1980 - RR $0.79,95 \%$ CI $0.65-0.96$ compared to 1990 - RR $0.91,95 \%$ CI $0.85-0.99)$, possibly related to the use of more potent immunosuppression (Iordanous, Seymour et al. 2009). The relationship between donor hypertension or lipid level and graft outcomes in this study remains unclear. Studies examining the association between donor obesity and donor urinary abnormalities (i.e. presence of proteinuria and/or haematuria pre-donation) are lacking. When examining live donor-recipient age difference, Ferrari $P$ et al demonstrated that live donor-recipient pairs with $\geq 30$ years age difference had similar graft and patient outcomes as those with lesser donor-recipient age difference suggesting large discrepancy in donor-recipient age difference should not discourage the decision for transplantation (Ferrari, Lim et al. 2011).

It is important to acknowledge that these are retrospective studies and therefore do not clearly establish causality between live donor factors and renal graft outcomes. Nevertheless, identifying unfavorable live donor characteristics could complement the assessments of recipients in stratifying their post-transplant risk of graft dysfunction or failure.

\section{ABO-incompatible and desensitization programs}

The complexity of live- and deceased donor transplantation has evolved over the years such that many transplanting centres are performing ABO-incompatible transplants and desensitizing highly allo-sensitized transplant candidates to improve their transplant potential. Other innovative programs that have been established to enhance live-donor transplantation include the paired kidney exchange program (as a strategy to overcome incompatible transplants) and tumour-resected kidney transplant program whereby patients with small renal tumours are considered for kidney donation following radical nephrectomy and resection of renal tumour. 


\subsection{ABO-incompatible live-donor transplants}

Alexandre et al first described transplantation across the blood group barrier in 1987, but there has since been a broad expansion of this program worldwide (Alexandre G 1987). With the greater availability of more potent immunosuppression coupled with the capability to measure isohemagglutinin antibodies, the outcomes of ABO-incompatible livedonor kidney transplantation are comparable to compatible live-donor kidney transplantation (Crew and Ratner 2010). However, there continues to be an early significant risk of antibody-mediated rejection (AMR). The concept of blood group incompatible transplantation involves the removal of isohemagglutinin antibodies (i.e. antibodies formed against blood group antigen $\mathrm{A}$ and/or $\mathrm{B}$ ) to low levels using immunoabsorption technique (ABO antibody-specific) or plasmapheresis (not $\mathrm{ABO}$ antibody-specific) thereby avoiding hyperacute rejection following transplantation. Although splenectomy was once considered standard practice pre-blood group incompatible transplantation to prevent early AMR, the introduction of anti-CD20 antibody rituximab has largely eliminated the need for splenectomy achieving equivalent outcomes. However, the need for pre-transplant rituximab remains debatable (Tanabe, Ischida et al. 2009).

Tanabe et al recently reported on the outcome of 800 ABO-incompatible kidney transplants in Japan performed since 1989. The reported 5-year graft and patient survival in this cohort was $79 \%$ and $90 \%$ respectively (Tanabe K 2007). Acute AMR occurred in up to $30 \%$ of transplant recipients resulting in early graft loss in $10 \%$ of recipients with refractory AMR (Crew R 2010). Although acute AMR may be treated successfully with further immunoabsorption or plasmapheresis, recipients who develop AMR have poorer graft survival (AMR and no AMR - graft survival of $84 \%$ and $100 \%$ at 3 years and $49 \%$ and $95 \%$ at 8 years) and a greater risk of developing transplant glomerulopathy, especially in recipients with concurrent pre-transplant donor specific antibodies (DSA) (Einecke, Sis et al. 2009; Toki, Ishida et al. 2009). Acute AMR is less common after 3 months post-transplant, presumably related to the development of accommodation, a phenomenon of persistent anti-donor antibody in the absence of allograft injury (Dehoux and Gianello 2009).

\subsection{ABO-incompatible deceased donor transplants}

In 1991, an Organ Procurement Transplant Network (OPTN)/UNOS variance has approved a voluntary national allocation of blood group A2 and A2B deceased donor kidneys into blood group $\mathrm{B}$ and $\mathrm{O}$ transplant candidates to improve their transplant potential, although this allocation practice had already been adopted into clinical practice by the Midwest Transplant Network since 1986 (Nelson, Shield et al. 2002). As a result of this practice, 31\% more blood group B transplant candidates with low anti-A IgG titres received a transplant achieving comparable graft survival as those who had received blood group B kidneys using conventional immunosuppression (10 year graft survival was $72 \%$ and $69 \%$ respectively) (Bryan, Nelson et al. 2004; Bryan, Winklhofer et al. 2005). Recent analysis of the United States Renal Data System (USRDS) database between 1995 and 2006 demonstrated that blood group $\mathrm{O}$ and $\mathrm{B}$ recipients $(\mathrm{n}=238)$ who had received blood group A2 kidneys had significantly shorter waiting-time compared to blood group compatible transplants $(\mathrm{n}=149,880)$. Graft loss and patient survival were similar in blood group A2 to B or O recipients and blood group compatible recipients (Hurst, Sajjad et al. 2010). These favourable reports suggest that this strategy should be considered in allocation programs to enhance the transplant potential of appropriate blood group $\mathrm{B}$ and $\mathrm{O}$ transplant candidates with low anti-A titres. 


\subsection{Desensitization of highly-sensitized patients for live-donor transplantation}

There is an increasing number of transplant candidates who are allo-sensitized to HLA as a result of previous exposure to HLA antigens, typically following blood transfusions, prior transplantation and pregnancy. The presence of high levels of class I and/or II DSA (i.e. anti-HLA antibodies with reactivity against the potential donor leading to positive complement-dependent cytotoxicity [CDC] cross-match) is associated with poorer graft outcomes, including the development of acute and chronic AMR, transplant glomerulopathy and late graft loss (Eng, Bennett et al. 2008; Gloor, Winters et al. 2010; Eng, Bennett et al. 2011; Mujtaba, Goggins et al. 2011). A study by LeFaucheur et al demonstrated that the presence of DSA significantly reduces graft survival rates compared to recipients without DSA (1 year graft survival $-81 \%$ and $94 \%$ respectively and 8 years graft survival $47 \%$ and $78 \%$ respectively) (Lefaucheur, Suberbielle-Boissel et al. 2008) (Table 2). In addition, recent study by Mujtaba $M$ et al demonstrated that the 3-year graft survival in highlysensitized patients with lower total DSA (i.e. total mean fluorescent intensity [MFI] of <9500) was $100 \%$ compared to $76 \%$ in those with higher total DSA (i.e. total MFI >9500; $p=0.022$ ) (Mujtaba, Goggins et al. 2011).

Studies reporting the utilization of desensitization technique to allow transplantation in highly-sensitized transplant candidates have focused predominantly on live-donor transplantation, which allows early planning and implementation of treatment at a suitable time. With the greater understanding of HLA antigens and anti-HLA antibodies, innovative techniques have been established to allow live-door transplantation across a 'positive CDC cross-match' barrier. Combinations of rituximab, plasmapheresis and/or intravenous immunoglobulin (IVIg) have been used successfully to desensitize highly allo-sensitized transplant candidates, therefore allowing live-donor transplantation to occur safely (Jordan, Vo et al. 2003; Gloor and Stegall 2010). The typical desensitization regimens involve either a single high dose of IVIg or combination plasmapheresis with low dose IVIg, although the latter may be more effective in achieving a negative CDC cross-match (Gloor, DeGoey et al. 2003; Stegall, Gloor et al. 2006). The addition of rituximab remains debatable and unsubstantiated and splenectomy has largely been eliminated from most desensitization protocols (Locke, Zachary et al. 2007). Current literature indicates that transplantation could safely proceed if DSA intensity is lowered sufficiently to render a negative CDC cross-match and/or an IgG titre of $\leq 16$ by isohemagglutination. Following successful transplantation, ongoing monitoring of DSA and early recognition of AMR is crucial to avoid early graft loss. On re-exposure to donor antigens against which the recipient is sensitized, memory $B$ lymphocytes in their spleen, bone marrow and lymph nodes undergo an amnestic reaction leading to the development of antibody-producing cells, which can produce high levels of DSA within days or weeks suggesting positive cross-match kidney transplantation requires both pre- and post-transplantation interventions to continually suppress DSA levels. Despite advances in desensitization techniques, AMR and transplant glomerulopathy occur in over $30 \%$ and $45 \%$ respectively in live donor positive cross-match kidney transplantations (Gloor J 2010).

\subsection{Desensitization of highly-sensitized patients on deceased donor wait-list}

Desensitization of deceased donor transplant wait-list candidates with multiple anti-HLA antibodies to enhance their transplant potential remains debatable due to the uncertain availability of deceased donor kidneys and these patients may remain on the deceased donor transplant wait-list indefinitely (Table 2). Vo et al reported the successful transplantation of 6 
highly sensitized patients who received deceased donor kidneys following desensitization with IVIg ( $2 \mathrm{~g} / \mathrm{kg}$ on days 0 and 30$)$ and rituximab ( $1 \mathrm{~g}$ on days 7 and 22$)$ over a 4-week period. These patients were on the deceased donor wait-list for 144 \pm 89 months (range 60-324 months), but had waited only an additional $5 \pm 6$ months for a transplant. These patients achieved excellent graft and patient outcomes despite having a greater risk of acute rejection (Vo, Lukovsky et al. 2008). The same group reported an additional 45 successful deceased donor transplants in highly sensitized patients using a similar but modified desensitization approach using one instead of two doses of rituximab. In this cohort, desensitized patients waited for an additional $4.2 \pm 4.5$ months before receiving a deceased donor graft. Overall graft failure and death at 2 years were $80 \%$ and $91 \%$ respectively, but almost $30 \%$ of graft loss was directly attributed to AMR (Vo, Peng et al. 2010).

\begin{tabular}{|l|c|c|c|c|}
\hline & $\begin{array}{c}\text { Number of } \\
\text { patients }\end{array}$ & $\begin{array}{c}\text { AMR } \\
\text { incidence (\%) }\end{array}$ & $\begin{array}{c}\text { 1-year DCGS } \\
\mathbf{( \% )}\end{array}$ & $\begin{array}{c}\text { 2-year DCGS } \\
\text { (\%) }\end{array}$ \\
\hline $\begin{array}{l}\text { Lefaucheur et al } \\
(2008)\end{array}$ & 43 & 35 & 89 & 89 \\
\hline $\begin{array}{l}\text { Thielke et al } \\
(2009)\end{array}$ & 51 & 32 & 93 & 81 \\
\hline $\begin{array}{l}\text { Magee et al } \\
(2008)\end{array}$ & 28 & 39 & 92 & 89 \\
\hline $\begin{array}{l}\text { Gloor et al } \\
(2010)\end{array}$ & 119 & 41 & 89 & 89 \\
\hline $\begin{array}{l}\text { Haririan et al } \\
(2009)\end{array}$ & 41 & 12 & 90 & 85 \\
\hline Vo et al (2008) & 16 & 30 & 94 & Not reported \\
\hline Vo et al (2010)\# & 76 & 29 & 87 & 84 \\
\hline
\end{tabular}

Table 2. Incidence of antibody mediated rejection (AMR) and death-censored graft survival (DCGS) following positive-crossmatch kidney transplantation. \#Stratified by donor type DCGS at 1 and 2 years for live donor (LD) $90 \%$ and $90 \%$; for deceased donor (DD) $82 \%$ and $80 \%$.

\section{Innovative live-donor programs}

\subsection{Paired kidney exchange}

Blood group or cross-match incompatibility between a potential donor-recipient pair is often a major barrier for kidney transplantation. Paired kidney exchange (PKE), which was first described in 1986 (Rapaport F 1986), circumvents the incompatibility by allowing a livedonor to direct the donated kidney to a different but compatible recipient, with the intent that another donor will donate to the first donor's designated recipient (Delmonico 2004). Most PKE programs involves the use of computer-generated algorithms to create potential donor-recipient pairings using virtual databases containing patient characteristics along with blood group types and degree of sensitization (de Klerk, Keizer et al. 2005). There are several alternatives to the conventional 2-way or 3-way kidney paired donation types, such that an altruistic donor could create a domino paired donation (i.e. kidneys from altruistic 
donor set off a chain of simultaneous transplants terminating in a donation to a candidate on the deceased donor wait-list) (Gentry, Montgomery et al. 2011). Although overcoming incompatibility remains the primary focus of PKE, donor and recipients pairs may participate in the exchange in the hope of finding a better HLA-matched kidney or younger kidney amongst other reasons. Match rates for incompatible pairs can be as high as $50 \%$ (de Klerk M 2006) and as a result can increase transplant activity even in small populations by almost 10\% (Ferrari P 2009). Successful PKE programs have been established in the Netherlands, South Korea, United Kingdom, United States and more recently Australia.

\subsection{Tumour-resected kidney transplant program}

Transplantation of donor kidneys following ex-vivo resection of small kidney tumours is a novel source of donor kidneys that was first described in 1995 (Penn I 1995). Although these kidneys are clearly outside the standard criteria for donor kidneys coupled with the small but potential transmission of donor-derived malignancy into recipients, the success of such program in many countries is encouraging.

The largest reported case series of utilizing donor kidneys with small renal cancers comes from Australia. In this single-centre program, 43 patients were transplanted with kidneys removed from patients with $<3 \mathrm{~cm}$ incidentally detected renal cell cancer, majority of which were patients undergoing radical nephrectomy for presumed renal cell cancer. In this program, a vigorous informed consent was undertaken and only older transplant candidates $>60$ years of age or those with significant comorbidities were eligible to receive these kidneys (Nicol D 2008). In this program, patient survival at 1 and 5 years of recipients of tumour-resected kidney transplants was $92 \%$ and $88 \%$ respectively, compared to $98 \%$ and $74 \%$ patient survival for patients on the deceased donor wait-list $(\mathrm{n}=153)$ and $99 \%$ and $97 \%$ patient survival for recipients of LURD renal transplants $(\mathrm{n}=120$; $\log$ rank score $10.4, \mathrm{P}=$ 0.005) (Brook, Gibbons et al. 2010). There was one tumour recurrence occurring at 9 years post-transplantation, but it was unclear whether this was donor-derived. An additional 22 similar successful cases from United States and Japan were reported with no documented tumour recurrence (Buell J 2005; Mannami, Mannami et al. 2008).

\section{Deceased donor kidney transplantation}

There continues to be an enormous disparity between the availability of deceased-donor kidneys and potential recipients. This problem is further exacerbated by a greater acceptance of older ESKD patients for renal replacement therapy. In Australia, acceptance of ESKD patients aged 70-74 years for renal replacement therapy has increased from 390 per million population (pmp) in 2004, to $469 \mathrm{pmp}$ in 2008 (McDonald, Excell et al. 2009). Furthermore, the proportion of potential transplant candidates aged $>65$ years on the deceased donor wait-list has increased by 21\% between 2005 and 2008 (Chadban, McDonald et al. 2006; Campbell, McDonald et al. 2009). The Scientific Registry of Transplant Patients (SRTR) has recorded a similar increase of prevalent potential recipients aged $\geq 70$ years on the deceased donor wait-list, rising from 114 in 1990 to 2544 in 2004 (Rao, Merion et al. 2007). There has been little increase in deceased donor rates worldwide. In Australia, deceased donor rates have remained low at 11 donors pmp in 2009 (10 pmp in 2005), compared to $34 \mathrm{pmp}$ in Spain, $24 \mathrm{pmp}$ in United States and $17 \mathrm{pmp}$ in the United Kingdom (Excell, Hee et al. 2010; Fabre, Murphy et al. 2010). However, there has been an increase in 
acceptance of older donor kidneys in Australia, with the number of deceased donors aged $\geq 55$ years increasing 1.8-fold between 2001-03 to 2007-09 (Excell, Hee et al. 2010). Kidneys from older donors are associated with poorer graft outcomes including late graft loss, chronic allograft nephropathy and higher risk of cardiovascular mortality (Meier-Kriesche, Cibrik et al. 2002; Oppenheimer, Aljama et al. 2004); this is partially offset by the reduction in mortality associated with reduced wait-list time. In addition, female-to-male donation, major donor kidney weight/recipient weight inadequacy, cerebrovascular accidents (CVA) as the cause of donor death and the presence of donor comorbidities such as diabetes have an adverse impact on graft and/or patient survival (Feldman, Fazio et al. 1996; Giral, Nguyen et al. 2005; Ahmad, Cole et al. 2009; Shaheen, Shaheen et al. 2010). However, utilization of kidneys from deceased donors who had developed acute renal failure prior to organ procurement does not appear to have an unfavorable effect on graft outcome (Deroure, Kamar et al. 2010). A continuous kidney donor risk index has been developed using registry data to quantify expected graft survival for any given set of donor characteristics relative to a healthy 40-year old donor and may be useful as a decisionmaking tool at the time of the deceased donor kidney offer (Rao, Schaubel et al. 2009). However, the significance of such index in the different transplant eras or population groups remains unclear. In the remaining chapter, we will focus primarily on the use and outcomes of ECD and DCD donor kidneys, which have become important source of deceased donor kidneys over the last decade.

\subsection{Expanded-criteria donor (ECD) kidneys (Table 3)}

With the ongoing shortage of deceased donor kidneys coupled with the continued growth of potential transplant candidates, there has been an increase utilization of ECD kidneys. Compared with non-ECD kidneys, ECD kidneys are associated with poorer graft outcomes. Between 2005 and 2009 in Australia, there has been a 1.3-fold increase in the number of ECD kidneys (Excell, Hee et al. 2006; Excell, Hee et al. 2010)

In 2002, OPTN/UNOS Board of Directors established a definition of ECD kidneys, which was based on a retrospective review of 29,068 recipients from SRTR database (Port FK 2002). The term ECD kidneys was assigned based on a $\geq 70 \%$ greater risk of developing graft failure when compared to younger donor kidneys (aged between 10 and 39 years) and defined as any donor aged $\geq 60$ years, or any donor aged $50-59$ years, with two of the following three donor criteria: CVA death, terminal creatinine $>133 \mu \mathrm{mol} / \mathrm{L}$, or hypertension (Metzger, Delmonico et al. 2003). Although the concept of ECD focuses primarily on advanced donor age, other risk factors such as CVA, hypertension, diabetes and high serum creatinine were also taken into account (Cosio, Qiu et al. 1996; Ojo, Leichtman et al. 2000). Multiple studies have demonstrated that recipients of ECD kidneys have better survival compared to potential recipients on the waiting-list but long-term outcomes associated with ECD grafts remains unclear (Wolfe, Ashby et al. 1999; Ojo, Hanson et al. 2001).

Further modification of the definition of ECD kidneys has been proposed in an attempt to further improve the stratification and identification of donor kidneys with increased risk of early graft dysfunction or graft loss. In 2001, Nyberg et al devised the Deceased Donor Score (DDS), which incorporated several donor-derived factors that have been shown to independently affect graft outcomes (Nyberg SL 2001; Nyberg SL 2003). However, this score has not been adopted widely for clinical application. 
In a retrospective study of 2845 French transplant recipients aged $\geq 60$ years, ECD kidneys were associated with poorer graft survival compared to non-ECD kidneys (Savoye, Tamarelle et al. 2007). The difference in graft survival was $6.2 \%$ at 12 months and $14.2 \%$ at 5 years (adjusted relative risk [RR] of graft failure associated with ECD kidneys compared to non-ECD kidneys was 1.98, p <0.01). Nonetheless, survival of ECD recipients was superior to potential recipients remaining on the waiting list (adjusted RR of potential recipients on waiting-list compared to recipients of ECD and non-ECD kidneys were 2.32 and 3.78 respectively, $p<0.0001)$. Similarly, analysis of the SRTR between 1990 and 2005 demonstrated that recipients aged $\geq 70$ years receiving ECD or non-ECD deceased donor kidneys had a $56 \%$ lower mortality risk compared to wait-listed dialysis patients aged $\geq 70$ years (RR $0.59 ; 95 \%$ CI $0.53,0.65 ; \mathrm{p}<0.0001$ ), and this benefit persisted in elderly patients with diabetes and hypertension (Rao, Merion et al. 2007). As the unadjusted 1-year graft and death-censored graft survival (DCGS) of elderly transplant recipients were $81 \%$ and $90 \%$ respectively; and were $67 \%$ and $85 \%$ respectively at 3years, this suggested that a considerable proportion of these recipients die with functioning grafts.

A retrospective analysis of ANZDATA of 4466 deceased donor transplants between 1991 and 2005 reported poorer outcomes in recipients of ECD kidneys, compared to non-ECD kidneys (Collins, Chang et al. 2009). Compared to non-ECD kidneys, ECD kidneys were associated with poorer graft function and a greater risk of DGF, acute rejection and deathcensored graft failure (DCGF).

The observed reduction in graft survival in recipients of ECD kidneys is likely related to an increase in glomerulosclerosis with the associated reduction in functional nephron mass, which has been shown to correlate with an increased risk of DGF, graft loss and poorer graft function (Gaber, Moore et al. 1995). On average, the adjusted graft survival of ECD kidneys is $8 \%$ lower at 1 year and up to $20 \%$ lower at 3-5 years compared to non-ECD kidneys (Ojo AO 2001).

Although ECD kidneys are associated with poorer outcomes compared to non-ECD kidneys, the contribution of donor age, especially the upper acceptable age limit on graft outcomes amongst ECD grafts remains unclear. In a retrospective analysis of the UNOS/OPTN database, the impact of donor age on 9580 ECD kidneys were examined (Chavalitdhamrong, Gill et al. 2008). There was no association between donor age and acute rejection, although ECD kidneys from donors aged $\geq 70$ years had poorer function at 12 months compared to grafts from younger ECD donors. In an adjusted model, ECD kidneys from donors aged $\geq 70$ years were associated with an increased risk of graft failure and patient death compared to ECD kidneys from donors aged 50-69 years (hazard ratio [HR] 1.37 and 1.37 respectively, $\mathrm{p}<0.01$ ). When stratified by recipient age, ECD kidneys from donors aged $\geq 70$ years (compared to ECD 50-69 years) were associated with an increased risk of DCGF for recipients aged 41-60 years (HR 1.48, 95\% CI 1.06, 2.06; $\mathrm{p}=0.02$ ) but not for older recipients aged $>60$ years (HR 1.12, 95\% CI 0.86, 1.46; $p=0.40$ ), suggesting that older ECD kidneys may have a smaller unfavourable impact in older recipients. In contrast, an Italian study demonstrated that 3-year graft and patient survival was similar in recipients receiving ECD kidneys from donors $>75$ years and $<75$ years (Collini, Kalmar et al. 2009). This inconsistent finding may be explained by the greater use of double kidneys (from donors $>75$ years) in the Italian study.

As ECD kidneys are more susceptible to peri-transplant insults, strategies to reduce cold ischemic time, improve donor kidney preservation (Burdick JF) and preventing or reducing reperfusion injury using agents such as superoxide dismutase (Land W) or platelet- 
activating factor receptor antagonists (Grino JM) may be beneficial. However, these strategies have not translated to improvement in renal graft outcomes. Initial avoidance of calcineurin-inhibitors (CNI) in early post-transplant period has been suggested to reduce the risk of DGF in recipients of ECD kidneys but this approach has not been adopted widely. Although there is a lack of consensus amongst transplant physicians and surgeons regarding the allocation of ECD kidneys, most would advocate selective utilization of these kidneys for older recipients (particularly avoiding recipients $<40$ years) (Merion, Ashby et al. 2005; Schold and Meier-Kriesche 2006), for recipients with extended wait-time (Carter, Chan et al. 2005; Cecka, Cohen et al. 2006) or to consider dual graft transplantation into a single recipient to avoid unnecessary discard of older donor kidneys (Waiser, Schreiber et al. 2000; Tan, Alfrey et al. 2004).

\begin{tabular}{|c|c|c|c|}
\hline & $\begin{array}{c}\text { Donor/recipient } \\
\text { groups }\end{array}$ & Graft outcome & Patient outcome \\
\hline $\begin{array}{l}\text { Collins M et al } 2009 \\
\text { ANZDATA }(n=4466)\end{array}$ & $\begin{array}{l}\text { Non-ECD }<50 y \\
\text { Non-ECD 50-59y } \\
\text { ECD } 50-59 y \\
\text { ECD } \geq 60 y\end{array}$ & $\begin{array}{c}1 / 5 y \text { DCGS* } \\
94 \% / 88 \% \\
91 \% / 84 \% \\
87 \% / 81 \% \\
87 \% / 71 \% \\
\end{array}$ & $\begin{array}{c}1 / 5 y \text { patient survival } \\
97 \% \text { / } 92 \% \\
97 \% \text { / } 90 \% \\
97 \% \text { / } 89 \% \\
96 \% \text { / } 87 \% \\
\end{array}$ \\
\hline $\begin{array}{l}\text { Collini A et al } 2009 \\
\text { Single centre }(n=192)\end{array}$ & $\begin{array}{l}E C D>75 y \\
E C D<75 y\end{array}$ & $\begin{array}{c}\text { 1/3y graft survival } \\
73 \% / 64 \% \\
82 \% / 71 \% \\
\end{array}$ & $\begin{array}{c}10 y \text { patient survival } \\
81 \% / 81 \% \\
92 \% / 90 \% \\
\end{array}$ \\
\hline $\begin{array}{l}\text { Savoye E et al } 2009 \\
\text { Single centre }(n=2845)\end{array}$ & $\begin{array}{l}\text { Expanded criteria } 0^{\wedge} \\
\text { Expanded criteria } 1^{\wedge} \\
\text { Expanded criteria } 2^{\wedge} \\
\text { Expanded criteria } 3^{\wedge}\end{array}$ & $\begin{array}{c}\text { 1/5y graft survival\# } \\
93 \% / 83 \% \\
87 \% \text { / } 74 \% \\
87 \% / 65 \% \\
83 \% / 55 \% \\
\end{array}$ & $\begin{array}{c}\text { 1/5y patient survival } \\
\text { ECD - } 97 \% \text { / 67\% } \\
\text { Non-ECD - } 98 \% \text { / } \\
91 \%\end{array}$ \\
\hline $\begin{array}{l}\text { Chavalitdhamrong D et } \\
\text { al 2008; OPTN/UNOS } \\
\text { database }(n=9580)\end{array}$ & $\begin{array}{l}\text { ECD } 50-69 y \\
\text { ECD } \geq 70 y\end{array}$ & $\begin{array}{c}\text { /5y graft survival* } \\
69 \% / 55 \% \\
62 \% / 44 \%\end{array}$ & $\begin{array}{c}/ 5 y \text { patient survival } \\
82 \% / 71 \% \\
75 \% / 58 \%\end{array}$ \\
\hline
\end{tabular}

Table 3. Effect of expanded criteria donor on renal transplant outcomes. * $p<0.05$; \#analysis in patients aged $\geq 60$ years, $\wedge$ expanded criteria risk factors including donor aged $>60$ years, donor hypertension, donor diabetes, donor death from cerebrovascular accident.

Abbreviation: ANZDATA - Australia and New Zealand Dialysis and Transplant Registry, ECD - expanded criteria donor, OPTN - Organ Procurement Transplant Network, UNOS United Network of Organ Sharing, y - year(s). Adapted from Lim et al (Nephrol Dial Transplant 2010).

\subsection{Donation after cardiac death donor kidneys}

Over the last decade, the number of brain-death donors has steadily declined, in part attributed to changes in neurosurgical practice (Jüttler, Schwab et al. 2007). However, the use of DCD donor kidneys has increased substantially. In Australia, the number of DCD donors has increased from 1 to 42 between 2000 and 2009 (Excell, Hee et al. 2010), whereas in the United Kingdom, the proportion of DCD of all deceased donors has increased by $29 \%$ between 2000 and 2009 (Transplant 2010). The prolonged warm ischaemic period that invariably accompanies DCD kidney transplants is likely to explain the greater incidence of 
DGF (Locke, Segev et al. 2007). As a result, DCD kidneys are more likely to be allocated locally to minimize cold ischaemic time. Recent analysis of the UK transplant registry demonstrated that compared with brain-death donor kidney transplants, recipients of controlled DCD donor kidneys of Maastricht category 3 (defined as donors awaiting cardiac arrest following withdrawal of life-sustaining treatment in intensive care unit (Kootstra, Daemen et al. 1995)) was associated with a significantly greater risk of DGF but lower risk of acute rejection up to 3 months post-transplant (Figure 2). For primary but not repeat renal allograft recipients of DCD kidneys, overall 5-year graft survival was comparable to primary and repeat renal allograft recipients of brain-death donor kidneys in unadjusted and adjusted models. Repeat renal allograft recipients of DCD kidneys have a greater risk of primary non-function compared to primary renal allograft recipients of DCD kidneys. Increasing donor and recipient age, as well as prolonged cold ischaemic time but not the presence of DGF or HLA-matching were associated with poorer graft outcomes in primary renal allograft recipients of DCD kidneys (Summers, Johnson et al. 2010). With comparable transplant outcomes between brain-death and controlled DCD donor kidneys, DCD kidneys are considered an acceptable source of donor kidneys although particular attention in reducing cold ischaemic time and avoidance of large donor-recipient age differences and avoidance of allocating DCD kidneys to repeat renal allograft recipients may be appropriate.

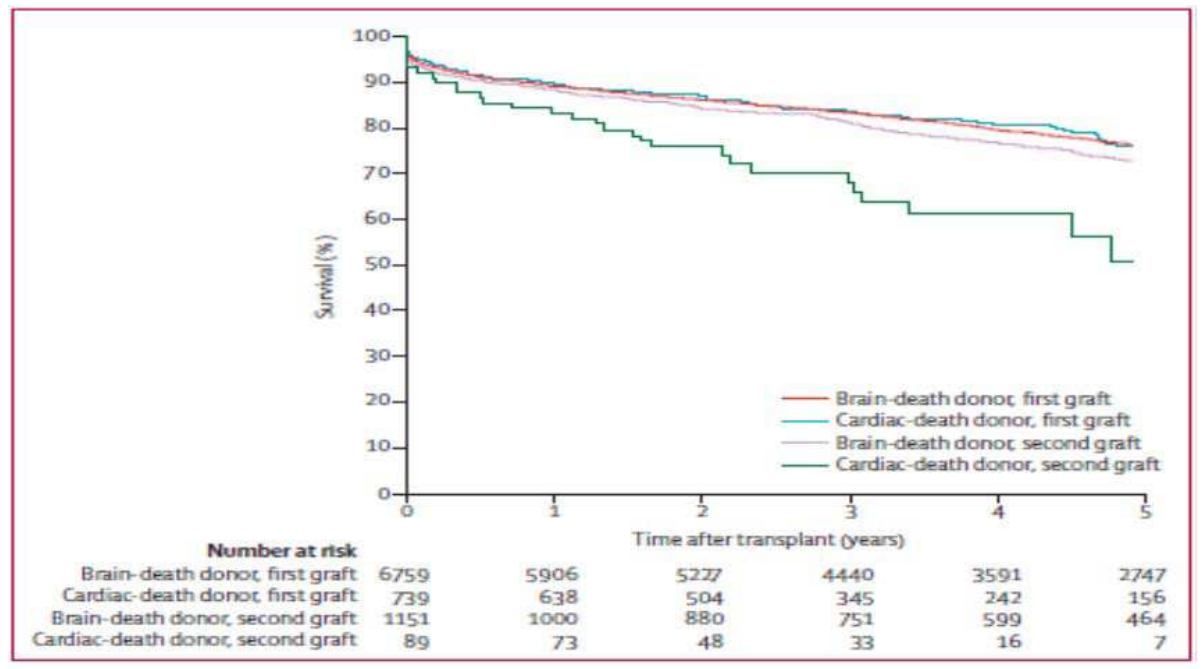

Fig. 2. Kaplan-Meier survival estimates comparing brain-death and cardiac-death donor grafts, stratified by primary and repeat grafts (adapted from Summers et al 2010).

\subsection{Utility-based allocation strategies to maximise overall functioning graft years}

Allocating younger donor kidneys to older potential recipients has raised concerns amongst many transplant physicians and surgeons, as many older recipients will die with functioning grafts. If these younger kidneys were re-allocated from older to younger recipients, a proportion may have continued to function for a substantial period in younger recipients. As older recipients have reduced life expectancies, adopting an allocation strategy that better matches the life expectancy of the donor kidney with that of the recipient 
may be more appropriate (Meier-Kriesche, Schold et al. 2005). Allocation strategies that have been examined included the concept of donor-recipient age-matching and the creation of a kidney allocation score (KAS) to improve the utility of deceased donor kidneys. These strategies will be discussed in this chapter.

\subsubsection{Age-matching}

Allocation of deceased donor kidneys according to donor-recipient age-matching avoids the allocation of younger donor kidneys to older recipients and older donor kidneys to younger recipients according to a single donor and recipient age cut-off value. The Eurotransplant Seniors Program (ESP) is an example of an age-matching allocation model that has been successfully implemented in the allocation of deceased donor kidneys.

\subsubsection{Eurotransplant seniors program}

The foundation of ESP, which was established in 1999, was to preferentially allocate older donor kidneys $\geq 65$ years to $\mathrm{ABO}$-compatible, unsensitized older recipients $\geq 65$ years receiving a primary graft (Cecka, Cohen et al. 2006). The ESP was designed to match the functional potential of donor kidneys $\geq 65$ years to the functional requirements of older recipients aged $\geq 65$ years. Although a degree of age-matching already occurred prior to the development of ESP such that the very young donor kidneys were seldom allocated to older recipients, this may be explained by younger healthier potential recipients near the top of the list declining a suboptimal donor graft, and therefore retain their place on the waiting list until a younger donor kidney becomes available. Similar practice also occurs in countries such as the United States and Australia where age-matching is not part of the standard allocation process (Segev 2009; Lim, Chang et al. 2010).

In ESP, donor kidneys were distributed locally to reduce cold ischaemic time, in an attempt to reduce the risk of DGF. Consequently, this program has not only resulted in an improvement in transplant access in older recipients by reducing wait-list times, younger recipients had also benefited from this program with improved access to younger donor kidneys (Smits, Persijn et al. 2002). Compared to 'old-to-any' (i.e. recipients of any age receiving a donor kidney $\geq 65$ years) and 'any-to-old' (i.e. recipients aged between 60-64 years receiving donor kidneys of any age) transplants (allocated via Eurotransplant Kidney Allocation System [ETKAS]), recipients of ESP had significantly lower risk of DGF; presumably related to the reduction in cold ischaemic time. However, ESP recipients had a greater risk of acute rejection, presumably related to a greater degree of HLA-mismatch(es), which was ignored in the allocation of ESP kidneys. One and 5-year DCGS in ESP recipients were similar to 'old-to-any' recipients ( 1 year - $83 \%$ and $81 \%$ respectively; 5 years $-67 \%$ for both groups) but were inferior compared to 'any-to-old' recipients ( 1 year $90 \%$ and 5 years $81 \%$ ) (Table 4). When stratified by donor age, the 1 and 5-year graft survival in the ESP group was $75 \%$ and $47 \%$ compared to $74 \%$ and $53 \%$ for 'any-to-old' recipients with older donors aged $\geq 60$ years $(\mathrm{p}=0.38$ ) and $85 \%$ and $67 \%$ for 'any-to-old' recipients with younger donors aged $<60$ years $(\mathrm{p}<0.001)$ suggesting older recipients receiving older donor kidneys allocated through the ETKAS system had similar outcome as ESP recipients. Although the risk of DGF was reduced in ESP recipients, this remained an important predictor of graft outcomes indicating that DGF may have a greater adverse impact on graft outcome in older recipients receiving older donor kidneys. It is conceivable that strategies to reduce the risk of DGF in ESP recipients (e.g. attempts to further reduce cold ischaemia) may lead to an 
improvement in graft and patient outcomes. An important and often overlooked finding in this study is that younger recipients of older donor kidneys have poorer survival, similar to that of the 'any-to-old' recipients allocated through the ETKAS system (Table 4).

Eurotransplant Senior DR-compatible Program is a new future initiative of the ESP to preferentially allocate kidneys to recipients with 0 HLA-DR mismatches and therefore potentially reducing the risk of rejection (de Fijter 2009). The outcome of this approach will be prospectively evaluated in the coming years.

\subsubsection{Simulated age-matching allocation of deceased donor kidneys}

In Australia, utilization of older donors has steadily increased, with donors aged $\geq 55$ years increasing from 134 to 241 between 2001-03 and 2007-09 (i.e. an increase of 16\% of overall donors) (Excell, Hee et al. 2010). A recent ANZDATA registry study of 4616 renal transplant recipients has demonstrated that the adoption an age-matching allocation model would lead to substantial improvement in the number of functioning graft years and associated cost savings (Lim, Chang et al. 2010). In this study, recipients $\geq 55$ years had more than a 2.5 -fold increased risk of death with functioning graft compared to recipients $<55$ years (HR 2.84, $95 \%$ CI 1.97, 4.10 for $0-1$ year; HR 2.78, 95\%CI 2.19, 3.53 for $1-8$ years and HR 4.44, 95\%CI $3.10,6.35$ for $>8$ years; all p-values $<0.01)$. However, the risk of early $(<1$ year) and late $(>8$ years) DCGF was similar in younger and older recipients. Compared with younger donor grafts, older donor grafts $\geq 60$ years were associated with a significant increased risk of DCGF, death with functioning graft and poorer post-transplant graft function. The application of an age-matching allocation model to this cohort would result in an additional 262 mean functioning graft years, which equates to $\$ 11.8-21.7$ million dialysis cost savings (cost per patient per year on dialysis $\$ 45,000-\$ 83,000$ ) (Cass, Chadban et al. 2006). Similarly, analysis of the SRTR database of 74,998 deceased donor transplants performed between 1990 and 2002 demonstrated that if older recipients aged 60-64 years received younger donor grafts aged 15-50 years, the application of age-matching allocation would have increased graft life by 27,500 years, with estimated cost savings in excess of 1 billion dollars (MeierKriesche, Schold et al. 2005). However, at an individual level, the absolute impact of agematching appears less impressive. In the ANZDATA study by Lim et al, Younger recipients of younger donor kidneys would on average have an additional 3 functioning graft years compared to older recipients receiving younger donor kidneys (11.6 vs 8.7 mean graft years respectively) and the negative impact of older donor kidneys on functioning graft years appears to be greater for younger compared to older recipients (9.3 vs 7.1 mean graft years respectively) (Table 4 ).

Retrospective analysis of the OPTN database demonstrated that for every 1 year increase in donor age, the risk of graft failure (HR 1.01, $\mathrm{p}<0.001)$ and death with functioning graft (HR 1.004, $\mathrm{p}<0.001$ ) was increased substantially (Moers, Kornmann et al. 2009). The negative impact of donor age on graft survival appears maximal between donors aged between 36 to 40 years (Keith, Demattos et al. 2004). In a simulated age-matching allocation system, the reallocation of older donor grafts $\geq 65$ years from younger recipients $<65$ years (old-toyoung) to older recipients $\geq 65$ years (old-to-old) would result in an absolute reduction in 10 year graft survival by $8 \%$ (from $21 \%$ to $13 \%$, p<0.001), whereas reallocation of donor kidneys $<65$ years from recipients $\geq 65$ years (young-to-old) to younger recipients $<65$ years (youngto-young) would result in an improvement in 10-year graft survival by $7 \%$ (19\% to $26 \%$, $\mathrm{p}=0.40$ ). Unlike the ANZDATA study, there was no net benefit of implementing an old-forold allocation system with regards to overall functional graft years (Table 4). 


\subsubsection{Kidney allocation score}

In 2004, a subcommittee of the UNOS/OPTN recommended that the establishment of a Kidney Allocation Score (KAS) based on Life Years From Transplant (LYFT - measures transplant utility), combined with panel reactive antibody (PRA), Donor Profile Index (DPI measures donor quality) and dialysis time (measures transplant equity) could potentially lead to an increase in the total number of life years gained from a restricted number of available deceased donor kidneys (Wolfe, McCullough et al. 2009; OPTN 2010). LYFT is defined as the additional years of life that a potential transplant recipient could expect to gain as a consequence of the transplant as compared to not receiving a transplant. LYFT is calculated from an equation generated by statistical modeling of historical data combining

\begin{tabular}{|c|c|c|c|}
\hline & $\begin{array}{c}\text { Donor/ } \\
\text { recipient groups }\end{array}$ & Graft outcome & Patient outcome \\
\hline $\begin{array}{l}\text { Frei U et al } 2008 \\
\text { ESP/ETKAS^ } \\
(n=3539)\end{array}$ & $\begin{array}{l}\mathrm{D} / \mathrm{R} \geq 55(\mathrm{ESP}) \\
\mathrm{D} \geq 65 / \mathrm{R}-\text { any age } \\
\mathrm{D}-\text { any age / } \mathrm{R} 60-64\end{array}$ & $\begin{array}{c}\text { 5y patient DCGS* } \\
67 \% \\
67 \% \\
81 \%\end{array}$ & $\begin{array}{c}5 y \text { patient survival } \\
60 \% \\
71 \% \\
74 \%\end{array}$ \\
\hline $\begin{array}{l}\text { Lim Wet al } 2010 \\
\text { ANZDATA } \\
(n=4616)\end{array}$ & $\begin{array}{l}\mathrm{D}<60 / R<55 \\
\mathrm{D}<60 / R \geq 55 \\
\mathrm{D} \geq 60 / \mathrm{R}<55 \\
\mathrm{D} \geq 60 / \mathrm{R} \geq 55\end{array}$ & $\begin{array}{c}\text { Mean graft years } \\
11.6 \\
9.3 \\
8.7 \\
7.1\end{array}$ & NR \\
\hline $\begin{array}{l}\text { Keith D et al } 2004 \\
\text { OPTN Registry } \\
(n=50,322)\end{array}$ & $\begin{array}{l}\text { D 30-41/ R 0-40 } \\
\text { D 30-41 / R } \geq 55 \\
D \geq 55 / R ~ 0-40 \\
D \geq 55 / R \geq 55\end{array}$ & NR & $\begin{array}{c}10 y \text { patient survival } \\
82 \% \\
45 \% \\
76 \% \\
35 \%\end{array}$ \\
\hline $\begin{array}{l}\text { Moers C et al } 2009 \\
\text { OPTN Registry } \\
(n=99,860)\end{array}$ & $\begin{array}{l}\mathrm{D}<65 / R<65 \\
\mathrm{D}<65 / \mathrm{R} \geq 65 \\
\mathrm{D} \geq 65 / \mathrm{R}<65 \\
\mathrm{D} \geq 65 / \mathrm{R} \geq 65\end{array}$ & $\begin{array}{c}10 y \text { graft survival } \\
\text { NR } \\
19 \% \\
21 \% \\
\text { NR }\end{array}$ & $\begin{array}{l}\text { DFG } \\
\text { NR } \\
56 \% \\
40 \% \\
\text { NR }\end{array}$ \\
\hline $\begin{array}{l}\text { Waiser et al } 2000 \\
\text { Single centre } \\
(n=1269)\end{array}$ & $\begin{array}{l}D \leq 55 / R \leq 55 \\
D \leq 55 / R>55 \\
D>55 / R \leq 55 \\
D>55 / R>55\end{array}$ & $\begin{array}{c}8 y \text { graft survival }^{*} \\
50 \% \\
53 \% \\
21 \% \\
57 \%\end{array}$ & $\begin{array}{c}D F G \\
11 \% \\
27 \% \\
2 \% \\
26 \%\end{array}$ \\
\hline
\end{tabular}

Table 4. Effect of age-matching allocation on graft and patient outcomes. ${ }^{*} \mathrm{p}<0.05$; $\wedge$ Prospective data. Abbreviation: ESP - Eurotransplant Senior Program, ETKAS Eurotransplant Kidney Allocation System, ANZDATA - Australia and New Zealand Dialysis and Transplant Registry, OPTN - Organ Procurement Transplant Network, D donor, $\mathrm{R}$ - recipient, DCGS - death-censored graft survival, DFG - death with functioning graft, y - year(s), NR - not reported. Adapted from Lim et al (Nephrol Dial Transplant 2010). 
the observed biological effects of patient and donor characteristics on survival. The equation created had a C-value of 0.75 , that is the equation predicted the potential transplant recipients with the longer lifetime $75 \%$ of the time, although the equation may be inaccurate for the prediction of lifetimes for potential transplant candidates with characteristics that differ from the historical group. A C-value of 0.75 is comparable to the model for end-stage liver disease (MELD) with a C-value of 0.64 , commonly used by many transplanting centres to prioritize patients for liver transplantation based on expected survival (Sharma, Schaubel et al. 2008). In addition, based on DPI, the kidneys with the longest survival potential will be allocated according to the combined score of LYFT ( $80 \%$ of total score) and dialysis time/PRA ( $20 \%$ of total score), whereas kidneys with lesser potential for long-term survival will be allocated according to dialysis time and PRA, such that better donor kidneys are allocated to younger potential recipients, who will have the longest expected LYFT. Older potential recipients, who will have a lower expected LYFT and potential recipients with the longest dialysis time will be less likely to receive better donor kidneys but may have an advantage in being allocated shorter-lived kidneys more rapidly (i.e. shorter waiting-time). If deceased donor kidney allocation was based on the KAS, there would a total expected increase in LYFT of 2642 years during a single year of allocation as compared with the current allocation system in the United States.

A perception that organ allocation is occurring in an inequitable manner could potentially reduce organ donor rates. Nevertheless, the utilization of KAS may improve allocation based solely on age-matching, with other patient factors such as diabetes, which are known to adversely affect graft and patient survival, are taken into account in the calculation of LYFT (Machnicki, Pinsky et al. 2009).

\subsubsection{Positives and negatives of implementing utility-based allocation models}

It remains unclear whether the implementation of utility-based allocation models will achieve a better balance between utility and equity. While kidney transplantation is more cost effective than dialysis, it will take considerable time for the expected lower long-term cost to offset the high initial cost associated with transplantation. In older recipients who are more likely to die with a functioning graft, the expense of transplantation may not be acceptable, on an economic basis, especially with a high-quality donor kidney.

Although adoption of an allocation model based on LYFT is likely to increase functioning graft years, this model is difficult to implement and may even be perceived as being discriminatory to potential 'high-risk' potential recipients (e.g. indigenous and highly sensitised potential recipients) who will have a higher predicted graft loss, resulting in a lower LYFT (Young and Gaston 2000; Young and Gaston 2005). The applicability of LYFT based on historical data to more recent eras and patient cohorts, where there may be differing clinical practices and use of novel immunosuppressive agents remains uncertain. In addition, the optimal weighting of DPI, dialysis time or other factors in the calculation of KAS remains undecided. Although not directly considered in the KAS and age-matching allocation models, KAS may indirectly take into consideration social equity and possibly quality of life, assuming that younger recipients receiving younger donor kidneys will have a longer lifespan and therefore greater contribution to society compared to older recipients (Laupacis, Keown et al. 1996). In contrast, age-matching allocation is simpler but chronological age is often a poor estimate of physiological age and therefore, allocation policy based solely on age-matching could potentially disadvantage a number of healthy older potential recipients. 


\section{Conclusion}

With the continuing shortage of deceased donor organs coupled with the increased utilization of marginal live and deceased donors including ECD and DCD donor kidneys, there have been considerable interest in examining the outcomes of these grafts. Over the last decade, there has been an expansion of innovative transplant programs, including paired exchange and tumour-resected kidney transplant programs, which has helped to overcome incompatible transplants and increase donor kidney pool respectively. In this chapter, understanding the association between live and deceased donor characteristics and transplant outcomes will assist clinicians and potential recipients in the informed process of donor selection as well as the prediction of graft outcomes following transplantation.

\section{References}

Ahmad, M., E. Cole, et al. (2009). "Impact of deceased donor diabetes mellitus on kidney transplant outcomes: a propensity score-matched study." Transplantation 88(2): 251-60.

Alexandre G, S. J., De Bruyère $M$, Latinne D, Reding R, Gianello P, Carlier M, Pirson Y (1987). "Present experiences in a series of 26 ABO-incompatible living donor renal allografts." Transplant Proceedings 19(6): 4538-4542.

Bia, M. J., E. L. Ramos, et al. (1995). "Evaluation of living renal donors. The current practice of US transplant centers." Transplantation 60(4): 322-7.

Bloembergen, W. E., F. K. Port, et al. (1996). "Gender discrepancies in living related renal transplant donors and recipients." J Am Soc Nephrol 7(8): 1139-44.

Brenner, B. M., R. A. Cohen, et al. (1992). "In renal transplantation, one size may not fit all." J Am Soc Nephrol 3(2): 162-9.

Brenner, B. M., E. V. Lawler, et al. (1996). "The hyperfiltration theory: a paradigm shift in nephrology." Kidney Int 49(6): 1774-7.

Brook, N., N. Gibbons, et al. (2010). "Outcomes of transplants from patients with small renal tumours, live unrelated donors and dialysis wait-listed patients." Transpl Int 23(5): 476-83.

Bryan, C., P. Nelson, et al. (2004). "Transplantation of A2 and A2B kidneys from deceased donors into B waiting list candidates increases their transplantation rate." Clin Transpl: 127-33.

Bryan, C., F. Winklhofer, et al. (2005). "Improving access to kidney transplantation without decreasing graft survival: long-term outcomes of blood group A2/A2B deceased donor kidneys in B recipients." Transplantation 80(1): 75-80.

Buell J, H. M., Thomas M, Munda R, Alloway R, First M, Woodle E (2005). "Donor kidneys with small renal cell cancers: can they be transplanted?" Transplant Proceedings 37(2): 581-582.

Burdick JF, R. J., McBride MA, Kauffman HM, Bennett LE (1997). "National impact of pulsatile perfusion on cadaveric kidney transplantation." Transplantation 64(12): 4.

Campbell, S., S. McDonald, et al. (2009). Transplant Waiting List. The Thirty Second Report Australia and New Zealand Dialysis and Transplant Registry. S. McDonald, L. Excell and B. Livingston. Adelaide. 
Campbell, S., S. McDonald, et al. (2009). Chapter 8 : Transplantation. ANZDATA Registry 32nd Annual Report. Adelaide, South Australia, Australia and New Zealand Dialysis and Transplant Registry (ANZDATA).

Carter, J., S. Chan, et al. (2005). "Expanded criteria donor kidney allocation: marked decrease in cold ischemia and delayed graft function at a single center." Am J Transplant 5(11): 2745-53.

Cass, A., S. Chadban, et al. (2006). Economic impact of end-stage kidney disease in Australia. K. H. Australia.

Cecka, J., B. Cohen, et al. (2006). "Could more effective use of kidneys recovered from older deceased donors result in more kidney transplants for older patients?" Transplantation 81(7): 966-70.

Cecka, J. M. (1995). "Living donor transplants." Clin Transpl: 363-77.

Chadban, S., S. McDonald, et al. (2006). Transplant Waiting List. The Twenty Ninth Report: Australia and New Zealand Dialysis and Transplant Registry. S. McDonald, S. Chang and L. Excell. Adelaide.

Chavalitdhamrong, D., J. Gill, et al. (2008). "Patient and graft outcomes from deceased kidney donors age 70 years and older: an analysis of the Organ Procurement Transplant Network/United Network of Organ Sharing database." Transplantation 85(11): 1573-9.

Collini, A., P. Kalmar, et al. (2009). "Renal transplant from very old donors: how far can we go?" Transplantation 87(12): 1830-6.

Collins, M., S. Chang, et al. (2009). "Outcomes of transplantation using kidneys from donors meeting expanded criteria in Australia and New Zealand, 1991 to 2005." Transplantation 87(8): 1201-9.

Cosio, F., W. Qiu, et al. (1996). "Factors related to the donor organ are major determinants of renal allograft function and survival." Transplantation 62(11): 1571-6.

Crew, R. and L. Ratner (2010). "ABO-incompatible kidney transplantation: current practice and the decade ahead." Curr Opin Organ Transplant 15: 526-30.

Crew R, R. L. (2010). "ABO-incompatible kidney transplantation: current practice and the decade ahead." Current Opinion in Organ Transplantation 15: 526-530.

de Fijter, J. (2009). "An old virtue to improve senior programs." Transpl Int 22(3): 259-68.

de Klerk, M., K. Keizer, et al. (2005). "The Dutch national living donor kidney exchange program." Am J Transplant 5(9): 2302-5.

de Klerk M, W. M., Haase-Kromwijk B, Claas F, Weimar W (2006). "A highly efficient living donor kidney exchange program for both blood type and crossmatch incompatible donor-recipient combinations." Transplantation 82(12): 1616-1620.

De Meester, J. (1998). Kidney: Donation, Waiting Lists and Transplants. Eurotransplant International Foundation Annual Report 1998 [internet]. B. Cohen, G. Persijn and J. De Meester. Leiden (Netherlands), Eurotransplant.

Dehoux, J. and P. Gianello (2009). "Accomodation and antibodies." Transpl Immunol 21: 106-10.

Delmonico, F. (2004). "Exchanging kidneys - advances in living-donor transplantation." N Engl J Med 350(18): 1812-14. 
Deroure, B., N. Kamar, et al. (2010). "Expanding the criteria of renal kidneys for transplantation: use of donors with acute renal failure." Nephrol Dial Transplant 25(6): 1980-6.

Donelly, P., P. Oman, et al. (1995). "Predialysis living donor renal transplantation: Is it still the 'gold standard' for cost, convenience and graft survival." Transplant Proc 27: 1444-6.

Einecke, G., B. Sis, et al. (2009). "Antibody-mediated microcirculation injury is the major cause of late kidney transplant failure." Am J Transplant 9(11): 2520-31.

Eng, H., G. Bennett, et al. (2011). "Donor HLA Specific Antibodies Predict Development and Define Prognosis in Transplant Glomerulopathy." Hum Immunol.

Eng, H., G. Bennett, et al. (2008). "Anti-HLA donor-specific antibodies detected in positive Bcell crossmatches by Luminex predict late graft loss." Am J Transplant 8(11): 2335-42.

ERA-EDTA Registry (2010). ERA-EDTA Annual Report 2008 [internet]. Amsterdam (Netherlands).

Excell, L., K. Hee, et al. (2006). ANZOD Registry Report 2006. Australia and New Zealand Organ Donation Registry. L. Excell, K. Hee and G. Russ. Adelaide.

Excell, L., K. Hee, et al. (2010). ANZOD Registry Report 2010. Australia and New Zealand Organ Donation Registry. L. Excell, K. Hee and G. Russ. Adelaide.

Excell, L., K. Hee, et al. (2010). ANZOD Registry Report 2010. ANZOD Registry Report. L. Excell, K. Hee and G. Russ. Adelaide, Australia and New Zealand Organ Donation Registry.

Fabre, J., P. Murphy, et al. (2010). "Presumed consent: a distraction in the quest for increasing rates of organ donation." BMJ 341: c4873.

Feldman, H., I. Fazio, et al. (1996). "Recipient body size and cadaveric renal allograft survival." J Am Soc Nephrol 7(1): 151-7.

Ferrari, P., W. Lim, et al. (2011). "Effect of donor-recipient age difference on graft function and survival in live-donor kidney transplantation." Nephrol Dial Transplant 26(2): 702-8.

Ferrari P, W. C., Christiansen F (2009). "Paired kidney donations to expand the living donor pool: the Western Australian experience." The Medical Journal of Australia 190(12): 700-703.

Frei, U., J. Noeldeke, et al. (2008). "Prospective age-matching in elderly kidney transplant recipients--a 5-year analysis of the Eurotransplant Senior Program." Am J Transplant 8(1): 50-7.

Fuggle, S. V., J. E. Allen, et al. (2010). "Factors affecting graft and patient survival after live donor kidney transplantation in the UK." Transplantation 89(6): 694-701.

Futagawa, Y., K. Waki, et al. (2005). "Living-unrelated donors yield higher graft survival rates than parental donors." Transplantation 79(9): 1169-74.

Gaber, L., L. Moore, et al. (1995). "Glomerulosclerosis as a determinant of posttransplant function of older donor renal allografts." Transplantation 60(4): 334-9.

Gentry, S., R. Montgomery, et al. (2011). "Kidney paired donation: fundamentals, limitations, and expansions." Am J Kidney Dis 57(1): 144-51. 
Ghods, A. J. and S. Savaj (2006). "Iranian Model of Paid and Regulated Living-Unrelated Kidney Donation." Clinical Journal of the American Society of Nephrology 1(6): 1136-1145.

Giral, M., J. Nguyen, et al. (2005). "Impact of graft mass on the clinical outcome of kidney transplants." J Am Soc Nephrol 16(1): 261-8.

Gjertson, D. W. and J. M. Cecka (2000). "Living unrelated donor kidney transplantation." Kidney Int 58(2): 491-9.

Gloor, J., S. DeGoey, et al. (2003). "Overcoming a positive crossmatch in living-donor kidney transplantation." Am J Transplant 3(8): 1017-23.

Gloor, J. and M. Stegall (2010). "Sensitized renal transplant recipients: current protocols and future directions." Nat Rev Nephrol 6(5): 297-306.

Gloor, J., J. Winters, et al. (2010). "Baseline donor-specific antibody levels and outcomes in positive crossmatch kidney transplantation." Am J Transplant 10(3): 582-9.

Gloor J, W. L., Cornell L, Fix L, DrGoey S, Knauer R, Cosio F, Gandhi M, Kremers W, Stegall M (2010). "Baseline donor-specific antibody levels and outcomes in positive crossmatch kidney transplantation." American Journal of Transplantation 10: 582-589.

Grino JM (1994). "BN 52021: a platelet activating factor antagonist for preventing posttransplant renal failure. A double-blind, randomized study. The BN 52021 Study Group in Renal Transplantation." Annals of Internal Medicine 121(5): 12.

Horvat, L. D., S. Z. Shariff, et al. (2009). "Global trends in the rates of living kidney donation." Kidney Int 75(10): 1088-98.

Humar, A., B. Durand, et al. (2000). "Living unrelated donors in kidney transplants: better long-term results than with non-HLA-identical living related donors?" Transplantation 69(9): 1942-5.

Hurst, F., S. Sajjad, et al. (2010). "Transplantation of A2 Kidneys into B and O Recipients Leads to Reduction in Waiting Time: USRDS Experience." Transplantation 89: 13961402.

Iordanous, Y., N. Seymour, et al. (2009). "Recipient outcomes for expanded criteria living kidney donors: the disconnect between current evidence and practice." Am J Transplant 9(7): 1558-73.

Issa, N., B. Stephany, et al. (2007). "Donor factors influencing graft outcomes in live donor kidney transplantation." Transplantation 83(5): 593-9.

Jordan, S., A. Vo, et al. (2003). "Intravenous immune globulin treatment inhibits crossmatch positivity and allows for successful transplantation of incompatible organs in living-donor and cadaver recipients." Transplantation 76(4): 631-6.

Jüttler, E., S. Schwab, et al. (2007). "Decompressive Surgery for the Treatment of Malignant Infarction of the Middle Cerebral Artery (DESTINY): a randomized, controlled trial." Stroke 38(9): 2518-25.

Kayler, L. K., H. U. Meier-Kriesche, et al. (2002). "Gender imbalance in living donor renal transplantation." Transplantation 73(2): 248-52.

Kayler, L. K., C. S. Rasmussen, et al. (2003). "Gender imbalance and outcomes in living donor renal transplantation in the United States." Am J Transplant 3(4): 452-8.

Keith, D., A. Demattos, et al. (2004). "Effect of donor recipient age match on survival after first deceased donor renal transplantation." J Am Soc Nephrol 15(4): 1086-91. 
Kessler, M., M. Ladriere, et al. (2011). "Does pre-emptive kidney transplantation with a deceased donor improve outcomes? Results from a French transplant network." Transpl Int 24(3): 266-75.

Kootstra, G., J. Daemen, et al. (1995). "Categories of non-heart-beating donors." Transplant Proc 27: 2893-94.

Land W, S. H., Schleibner S, Illner WD, Abendroth D, Rutili G, Arfors KE, Messmer K (1994). "The beneficial effect of human recombinant superoxide dismutase on acute and chronic rejection events in recipients of cadaveric renal transplants." Transplantation 57(2): 7.

Laupacis, A., P. Keown, et al. (1996). "A study of the quality of life and cost-utility of renal transplantation." Kidney Int 50(1): 235-42.

Lefaucheur, C., C. Suberbielle-Boissel, et al. (2008). "Clinical relevance of preformed HLA donor-specific antibodies in kidney transplantation." Am J Transplant 8(2): 324-31.

Liem, Y. S. and W. Weimar (2009). "Early living-donor kidney transplantation: a review of the associated survival benefit." Transplantation 87(3): 317-8.

Lim, W., S. Chang, et al. (2010). "Donor-recipient age matching improves years of graft function in deceased-donor kidney transplantation." Nephrol Dial Transplant 25(9): 3082-9.

Lim, W. H., S. H. Chang, et al. (2007). "Parental donors in live-donor kidney transplantation associated with increased rejection rates and reduced glomerular filtration rates." Transplantation 84(8): 972-80.

Locke, J., D. Segev, et al. (2007). "Outcomes of kidneys from donors after cardiac death: implications for allocation and preservation." Am J Transplant 7: 1797-807.

Locke, J., A. Zachary, et al. (2007). "The utility of splenectomy as rescue treatment for severe acute antibody mediated rejection." Am J Transplant 7(4): 842-6.

Machnicki, G., B. Pinsky, et al. (2009). "Predictive ability of pretransplant comorbidities to predict long-term graft loss and death." Am J Transplant 9(3): 494-505.

Mahanty, H. D., W. S. Cherikh, et al. (2001). "Influence of pretransplant pregnancy on survival of renal allografts from living donors." Transplantation 72(2): 228-32.

Mange, K. C., M. M. Joffe, et al. (2001). "Effect of the use or nonuse of long-term dialysis on the subsequent survival of renal transplants from living donors." $\mathrm{N}$ Engl J Med 344(10): 726-31.

Mannami, M., R. Mannami, et al. (2008). "Last resort for renal transplant recipients, 'restored kidneys' from living donors/patients." Am J Transplant 8(4): 811-8.

McDonald, S., L. Excell, et al. (2009). New patient commencing treatment in 2008. Australia and New Zealand Dialysis and Transplant Registry. S. McDonald, L. Excell and B. Livingston. Adelaide: 1-12.

Meier-Kriesche, H., D. Cibrik, et al. (2002). "Interaction between donor and recipient age in determining the risk of chronic renal allograft failure." J Am Geriatr Soc 50(1): 14-7.

Meier-Kriesche, H., J. Schold, et al. (2005). "Kidneys from deceased donors: maximizing the value of a scarce resource." Am J Transplant 5: 1725-30.

Meier-Kriesche, H. U. and B. Kaplan (2002). "Waiting time on dialysis as the strongest modifiable risk factor for renal transplant outcomes: a paired donor kidney analysis." Transplantation 74(10): 1377-81. 
Merion, R., V. Ashby, et al. (2005). "Deceased-donor characteristics and the survival benefit of kidney transplantation." JAMA 294(21): 2726-33.

Metzger, R., F. Delmonico, et al. (2003). "Expanded criteria donors for kidney transplantation." Am J Transplant 3(Suppl 4): 114-25.

Miles, C. D., D. E. Schaubel, et al. (2008). "The role of donor-recipient relationship in long-term outcomes of living donor renal transplantation." Transplantation 85(10): 1483-8.

Milton, C., G. Russ, et al. (2008). "Pre-emptive renal transplantation from living donors in Australia: Effect on allograft and patient survival." Nephrology 13: 535-40.

Moers, C., N. Kornmann, et al. (2009). "The influence of deceased donor age and old-for-old allocation on kidney transplant outcome." Transplantation 88(4): 542-52.

Mujtaba, M., W. Goggins, et al. (2011). "The strength of donor-specific antibody is a more reliable predictor of antibody-mediated rejection than flow cytometry crossmatch analysis in desensitized kidney recipients." Clin Transplant 25(1): E96-102.

Nelson, P., C. r. Shield, et al. (2002). "Increased access to transplantation for blood group B cadaveric waiting list candidates by using A2 kidneys: time for a new national system?" Am J Transplant 2(1): 94-9.

Nicol D, P. J., Wall D, Griffin A, Campbell S, Isbel N, Hawley C, Johnson D (2008). "Kidneys from patients with small renal tumours: a novel source of kidneys for transplantation." British Journal of Urology International 102(2): 188-192.

Nyberg SL, M. A., Kremers WK, Thostenson JD, Larson TS, Prieto M, Ishitani MB, Sterioff S, Stegall MD (2003). "Improved scoring system to assess adult donors for cadaver renal transplantation." Am J Transplant 2(6): 6.

Nyberg SL, M. A., Rogers M, Harmsen WS, Velosa JA, Larson TS, Prieto M, Ishitani MB, Sterioff S, Stegall MD (2001). "Donor scoring system for cadaveric renal transplantation." Am J Transplant 1(2): 8.

Nyengaard JR, B. T. (1992). "Glomerular number and size in relation to age, kidney weight, and body surface in normal man (abstract)." The Anatomical Record 232(2): 7.

Oien, C. M., A. V. Reisaeter, et al. (2007). "Living donor kidney transplantation: the effects of donor age and gender on short- and long-term outcomes." Transplantation 83(5): 600-6.

Oien, C. M., A. V. Reisaeter, et al. (2005). "Gender imbalance among donors in living kidney transplantation: the Norwegian experience." Nephrol Dial Transplant 20(4): 783-9.

Ojo, A., J. Hanson, et al. (2001). "Survival in recipients of marginal cadaveric donor kidneys compared with other recipients and wait-listed transplant candidates." J Am Soc Nephrol 12(3): 589-97.

Ojo, A., A. Leichtman, et al. (2000). "Impact of pre-existing donor hypertension and diabetes mellitus on cadaveric renal transplant outcomes." Am J Kidney Dis 36(1): 153-9.

Ojo AO, H. (2001). "Survival in recipients of marginal cadaveric donor kidneys compared with other recipients and wait-listed transplant candidates." Journal of the American Society of Nephrology 12(3): 9.

Oosterlee, A. and A. Rahmel, Eds. (2008). Eurotransplant International Foundation Annual Report 2008 [internet]. Leiden (Netherlands), Eurotransplant.

Oppenheimer, F., P. Aljama, et al. (2004). "The impact of donor age on the results of renal transplantation." Nephrol Dial Transplant 19(Suppl 3): iii11-iii15. 
OPTN. (2010). "Kidney allocation policy development." http:/ /optn.transplant.hrsa.gov/kars.asp.

Penn I (1995). "Primary kidney tumors before and after renal transplantation." Transplantation 59(4): 480-485.

Poggio, E., S. Hila, et al. (2006). "Donor kidney volume and outcomes following live donor kidney transplantation." Am J Transplant 6(3): 616-24.

Port FK, B.-G. J., Metzger RA, Dykstra DM, Gillespie BW, Young EW, Delmonico FL, Wynn JJ, Merion RM, Wolfe RA, Held PJ (2002). "Donor characteristics associated with reduced graft survival: An approach to expanding the pool of kidney donors." Transplantation 74(9): 5.

Rao, P., R. Merion, et al. (2007). "Renal transplantation in elderly patients older than 70 years of age: results from the Scientific Registry of Transplant Recipients." Transplantation 83(8): 1069-74.

Rao, P., D. Schaubel, et al. (2009). "A comprehensive risk quantification score for deceased donor kidneys: the kidney donor risk index." Transplantation 88(2): 231-6.

Rapaport F (1986). "The case for a living emotionally related international kidney donor exchange registry." Transplant Proceedings 18(3 (Suppl. 2)): 5-9.

Rosenberg, J. C., B. Jones, et al. (2004). "Accelerated rejection following offspring-to-mother and husband-to-wife transplants." Clin Transplant 18(6): 729-33.

Savoye, E., D. Tamarelle, et al. (2007). "Survival benefits of kidney transplantation with expanded criteria deceased donors in patients aged 60 years and over." Transplantation 84(12): 1618-24.

Schaubel, D. E., D. E. Stewart, et al. (2000). "Sex inequality in kidney transplantation rates." Arch Intern Med 160(15): 2349-54.

Schold, J. and H. Meier-Kriesche (2006). "Which renal transplant candidates should accept marginal kidneys in exchange for a shorter waiting time on dialysis?" Clin J Am Soc Nephrol 1(3): 532-8.

Schweitzer, E. J., J. Wilson, et al. (2000). "Increased rates of donation with laparoscopic donor nephrectomy." Ann Surg 232(3): 392-400.

Segev, D. (2009). "Evaluating options for utility-based kidney allocation." Am J Transplant 9: 1513-8.

Shaheen, M., F. Shaheen, et al. (2010). "Impact of recipient and donor nonimmunologic factors on the outcome of deceased donor kidney transplantation." Transplant Proc 42(1): 273-6.

Sharma, P., D. Schaubel, et al. (2008). "Re-weighting the model for end-stage liver disease score components." Gastroenterology 135(5): 1575-81.

Smits, J., G. Persijn, et al. (2002). "Evaluation of the Eurotransplant Senior Program. The results of the first year." Am J Transplant 2: 664-70.

Stegall, M., J. Gloor, et al. (2006). "A comparison of plasmapheresis versus high-dose IVIG desensitization in renal allograft recipients with high levels of donor specific alloantibody." Am J Transplant 6: 346-51.

Summers, D., R. Johnson, et al. (2010). "Analysis of factors that aff ect outcome after transplantation of kidneys donated after cardiac death in the UK: a cohort study." Lancet 376: 1303-11. 
Tan, J., E. Alfrey, et al. (2004). "Dual-kidney transplantation with organs from expanded criteria donors: a long-term follow-up." Transplantation 78(5): 692-6.

Tanabe K (2007). "Japanese experience of ABO-incompatible living kidney transplantation." Transplantation 84(12 Suppl): S4-7.

Tanabe, K., H. Ischida, et al. (2009). "Evaluation of two different preconditioning regimens for ABO-incompatible living kidney donor transplantation. A comparison of splenectomy vs. rituximab-treated non-splenectomy preconditioning regimens." Contrib Nephrol 162: 61-74.

Terasaki, P. I., J. M. Cecka, et al. (1997). "Spousal and other living renal donor transplants." Clin Transpl: 269-84.

Terasaki, P. I., J. M. Cecka, et al. (1995). "High survival rates of kidney transplants from spousal and living unrelated donors." N Engl J Med 333(6): 333-6.

Toki, D., H. Ishida, et al. (2009). "Acute antibody-mediated rejection in living ABOincompatible kidney transplantation: long-term impact and risk factors." Am J Transplant 9(3): 567-77.

Transplant, N. H. S. B. a. (2010). "Transplant activityin the UK, 2008-2009." from http://www.organdonation.nhs.uk/ukt/statistics/transplant_activity_report/cur rent_activity_reports/ukt/2008_09/transplant_activity_uk_2008-09.pdf.

US Organ Procurement and Transplantion Network and Scientific Registry of Transplant Recipients (2009). US Organ Procurement and Transplantion Network and the Scientific Registry of Transplant Recipients Annual Report 2009: Transplant Data 1999-2008, US Department of Health and Human Services.

Vereerstraeten, P., M. Wissing, et al. (1999). "Male recipients of kidneys from female donors are at increased risk of graft loss from both rejection and technical failure." Clin Transplant 13(2): 181-6.

Vo, A., M. Lukovsky, et al. (2008). "Rituximab and intravenous immune globulin for desensitization during renal transplantation." N Engl J Med 359: 242-51.

Vo, A., A. Peng, et al. (2010). "Use of intravenous immune globulin and rituximab for desensitization of highly HLA-sensitized patients awaiting kidney transplantation." Transplantation 89: 1095-102.

Waiser, J., M. Schreiber, et al. (2000). "Age-matching in renal transplantation." Nephrol Dial Transplant 2000(15).

Wolfe, R., V. Ashby, et al. (1999). "Comparison of mortality in all patients on dialysis, patients on dialysis awaiting transplantation, and recipients of a first cadaveric transplant." N Engl J Med 341(23): 1725-30.

Wolfe, R., K. McCullough, et al. (2009). "Predictability of survival models for waiting list and transplant patients: calculating LYFT." Am J Transplant 9(7): 1523-7.

Young, C. and R. Gaston (2000). "Renal transplantation in black Americans." N Engl J Med 343(21): 1545-52.

Young, C. and R. Gaston (2005). "Understanding the influence of ethnicity on renal allograft survival." Am J Transplant 5: 2603-4.

Zeier, M., B. Dohler, et al. (2002). "The effect of donor gender on graft survival." J Am Soc Nephrol 13(10): 2570-6. 
Zimmerman, D., S. Donnelly, et al. (2000). "Gender disparity in living renal transplant donation." Am J Kidney Dis 36(3): 534-40. 


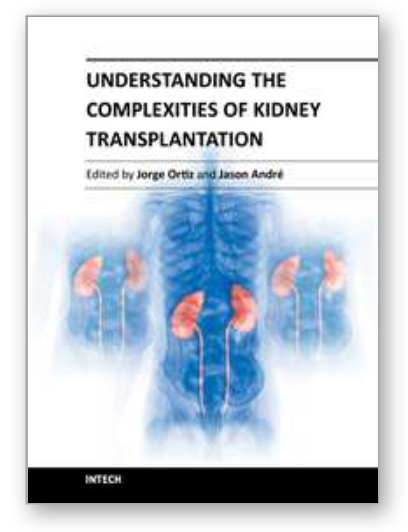

\author{
Understanding the Complexities of Kidney Transplantation \\ Edited by Prof. Jorge Ortiz
}

ISBN 978-953-307-819-9

Hard cover, 564 pages

Publisher InTech

Published online 06, September, 2011

Published in print edition September, 2011

Kidney transplantation is a complex field that incorporates several different specialties to manage the transplant patient. This book was created because of the importance of kidney transplantation. This volume focuses on the complexities of the transplant patient. In particular, there is a focus on the comorbidities and special considerations for a transplant patient and how they affect kidney transplant outcomes. Contributors to this book are from all over the world and are experts in their individual fields. They were all individually approached to add a chapter to this book and with their efforts this book was formed. Understanding the Complexities of Kidney Transplantation gives the reader an excellent foundation to build upon to truly understand kidney transplantation.

\title{
How to reference
}

In order to correctly reference this scholarly work, feel free to copy and paste the following:

Hung Do Nguyen, Kenneth Yong, Rebecca Croke and Wai H Lim (2011). The Impact of Donor Type and Quality on Renal Transplant Outcomes, Understanding the Complexities of Kidney Transplantation, Prof. Jorge Ortiz (Ed.), ISBN: 978-953-307-819-9, InTech, Available from:

http://www.intechopen.com/books/understanding-the-complexities-of-kidney-transplantation/the-impact-ofdonor-type-and-quality-on-renal-transplant-outcomes

\section{INTECH}

open science | open minds

\author{
InTech Europe \\ University Campus STeP Ri \\ Slavka Krautzeka 83/A \\ 51000 Rijeka, Croatia \\ Phone: +385 (51) 770447 \\ Fax: +385 (51) 686166 \\ www.intechopen.com
}

\author{
InTech China \\ Unit 405, Office Block, Hotel Equatorial Shanghai \\ No.65, Yan An Road (West), Shanghai, 200040, China \\ 中国上海市延安西路65号上海国际贵都大饭店办公楼405单元 \\ Phone: +86-21-62489820 \\ Fax: $+86-21-62489821$
}


(C) 2011 The Author(s). Licensee IntechOpen. This chapter is distributed under the terms of the Creative Commons Attribution-NonCommercialShareAlike-3.0 License, which permits use, distribution and reproduction for non-commercial purposes, provided the original is properly cited and derivative works building on this content are distributed under the same license. 